Short Communication

\title{
Properties Research of Overlay Welding Treatment on Glass- lined Anticorrosion Tube with a Small Diameter
}

\section{Guoqiang Xu}

College of Pipeline and Civil Engineering, China University of Petroleum (East China), Qingdao 266580, P R China

E-mail: xuguoqiang@upc.edu.cn

doi: $10.20964 / 2016.10 .45$

Received: 24 May 2016 / Accepted: 27 July 2016 / Published: 6 September 2016

In this present study, the mechanical and anticorrosion properties of the Ni625 undercoat on 20\# carbon steel prior to the welding process have been investigated by tensile, bending and hardness tests, and the electrochemical measurement. The absence of corrosion pits in the steels with Ni625 undercoat was investigated after $\mathrm{CO}_{2}$ corrosion tests and the corrosion rate was assessed at $4.2 \times 10^{-5} / \mathrm{mdd}$, revealing good anticorrosion qualities. Polarization surveys of the nickel materials in the chloride solutions displayed higher corrosion current densities relative to the situations of the steel, due to the high susceptibility to the pitting initiation on the nickel surface. Furthermore, Increasing the temperature of the corrosive environment from 30,60 and $80^{\circ} \mathrm{C}$ displayed higher corrosion current densities and negative corrosion potentials, suggesting the enhanced corrosion events. Notably, the mechanical quality of Ni625 undercoat on carbon steel reached the requirements of the empirical applications, and this material revealed good selection for the overlay welding. In this regard, the selection of Ni625 undercoat for the weld overlay on carbon steel is good qualities in mechanical and anticorrosion properties.

Keywords: glass-lined tube; overlay welding; corrosion; mechanical properties

\section{$\underline{\text { FULL TEXT }}$}

(C) 2016 The Authors. Published by ESG (www.electrochemsci.org). This article is an open access article distributed under the terms and conditions of the Creative Commons Attribution license (http://creativecommons.org/licenses/by/4.0/). 